\title{
El principio de la autonomía de la voluntad contractual vs el control jurisdiccional constitucional en los laudos arbitrales*
}

\author{
The principle of the autonomy of the \\ contractual will vs. The constitutional \\ jurisdictional control in the arbitral awards
}

\author{
MÓNICA MARÍA Fuentes MANCIPE** \\ IVÁN DARÍO HERNÁNDEZ RODRÍGUEZ***
}

\section{RESUMEN}

Con el pasar del tiempo en el derecho civil, comercial e internacional se ha puesto en tela de juicio el verdadero valor de los laudos arbitrales y el reconocimiento del derecho arbitral como justicia privada, gracias a la procedencia de la acción de tutela contra tales decisiones. Razón por la cual, el interés de escribir este artículo tiene como propósito el cuestionar la acción de tutela como un límite al principio de la autonomía de la voluntad privada de las partes cuando de elegir el arbitraje para dirimir controversias se trata.

* Fecha de recepción: 2 de mayo de 2019. Fecha de aceptación: 27 de junio de 2019. Para citar el artículo: Mancipe My Hernández I. "El principio de la autonomía de la voluntad contractual vs el control jurisdiccional constitucional en los laudos arbitrales", en Revist@ E-Mercatoria, vol. 18, n. ${ }^{\circ}$ 1, enero-junio, 2019. DOI: https://doi.org/10.18601/16923960. v18n1.03

** Magíster en Derecho Comercial internacional "International Bussines Law" de la Universidad Sapienza de Roma y Especialista en Derecho Comercial de la Universidad Externado de Colombia. Profesora e Investigadora de la Universidad La Gran Colombia. Contacto: monicafmancipe@gmail.com OR-CID:0000-0002-3695-8144.

*** Magíster en Derecho de la Universidad de los Andes y Especialista en Derecho constitucional de la Universidad del Rosario y Abogado de la Universidad La Gran Colombia. Contacto: Ivandariohernandezr@gmail.com. OR- CID: 0000-0002-2644-0608. 
En ese proceder y pese al reconocimiento estatal del arbitraje, como un mecanismo alternativo para la resolución de conflictos, según lo previsto en la Constitución Política de Colombia, el desarrollo legislativo y los tratados internacionales sobre la materia en particular, es de resaltar que el control constitucional generado por las altas cortes a los laudos arbitrales, específicamente el realizado por la Corte Constitucional en Colombia mediante la acción de tutela, se ha convertido en un tema de gran discusión entre los estudiosos del derecho y los abogados practicantes del derecho arbitral.

Con la procedencia de dicha acción se ha puesto en tela de juicio la validez, eficacia, celeridad, confidencialidad, economía e idoneidad de los laudos arbitrales, pues al parecer, la Corte Constitucional se ha venido pronunciando sobre aspectos materiales y no procesales es sus decisiones, que afectan la fuerza ejecutoria del laudo arbitral y a su vez generan inseguridad jurídica para quienes acuden a él.

Palabras Clave: Arbitraje, control jurisdiccional constitucional, recurso de anulación, recurso de revisión, acción de tutela, laudo arbitral, sentencia, Corte Constitucional, arbitro y juez.

\section{ABSTRACT}

With the passage of time in civil, commercial and international law, the true value of arbitration awards and the recognition of arbitral law as private justice has been questioned, thanks to the origin of the action of protection against decisions, then unique to the referees. Reason why the interest of writing this article has as its purpose to question, the action of guardianship as a limit to the autonomy of the private will of the parties when choosing the arbitration to settle their disputes is addressed.

Despite the state recognition of Arbitration, as an alternative mechanism for the resolution of conflicts, as provided for in the Political Constitution of Colombia, the legislative development and international treaties on the matter in particular, on occasion of the constitutional judicial control generated by the discharges Courts, specifically by the Constitutional Court of Colombia through the tutela action, it is noteworthy that, in recent years, this control has become the focus of arbitral law.

Since, with the provenance of this action, the validity, efficiency, speed, confidentiality, economy and suitability of the arbitration awards have been questioned, since apparently, the Constitutional Court has been ruling on material aspects and not procedural is their decisions, which affect the enforcement of the arbitral award and in turn generate legal uncertainty for those who come to him. 
Keywords: Arbitration, jurisdictional control, constitutional control, appeal for annulment, appeal for review, arbitration award, judgment, Constitutional Court, Arbitrator, Judge, writ of protection of fundamental rights.

\section{INTRODUCCIÓN}

Para comenzar, es de afirmar, que los mecanismos alternativos para la resolución de conflictos en la era de la globalización se han venido consolidado como una de las posibilidades más rentables y eficaces en términos empresariales y corporativos para la resolución de conflictos. Lo anterior, gracias a la potestad y a la fuerza contractual que en los últimos años le ha venido otorgado y reconociendo el Estado colombiano por intermedio del Principio de la autonomía de la voluntad contractual ${ }^{1}$ a las partes en la toma de decisiones cuando se perfecciona un negocio jurídico y a las prerrogativas concedidas en el ordenamiento jurídico, gracias a la costumbre mercantil y a la lex mercatoria, quienes prevén al arbitraje como un mecanismo eficaz, célere, especializado y recurrente en el mundo de los negocios para la resolución de controversias.

Siendo entonces a partir de esta visión, el objetivo principal de este artículo el cuestionar la acción de tutela como un límite a la autonomía de la voluntad privada de las partes cuando de elegir el arbitraje para dirimir sus controversias se trata. Con el fin de llegar a esta conclusión, este artículo comenzará con el estudio del principio de la autonomía de la voluntad contractual en el arbitraje, seguido del análisis del reconocimiento del derecho arbitral en el derecho colombiano, de manera posterior se procederá a la ilustrar sobre los laudos arbitrales como decisiones autónomas en el derecho colombiano. Finalmente, se expondrá el control jurisdiccional sobre tales decisiones a través del recurso extraordinario de anulación y revisión, así como el control constitucional sobre las mismas a través de la acción de tutela como limite al principio de la Autonomía de la voluntad contractual.

1 Cfr. Fernando Hinestrosa «Autonomía privada y tipicidad Contractual». Revista de Derecho Privado n. ${ }^{\circ} 24$ (Enero-Junio 2013): 2-11, a fin de entender el principio de la autonomía de la voluntad contractual como "el poder de disposición de los propios intereses por iniciativa personal, con estas expresiones, podría decirse, se trasunta un patrimonio cultural, jurídico y político varias veces milenario, denominado con distintos apelativos a lo largo del tiempo, $y$, como es apenas natural, concebido sucesivamente de conformidad con la ideología, no solo la imperante en la respectiva oportunidad, sino, más singularmente, la profesada por los redactores del respectivo ordenamiento, los jurisprudentes y el doctrinante que se quiera citar". 


\section{EL PRINCIPIO DE LA AUTONOMÍA DE LA VOLUNTAD CONTRACTUAL EN EL ARBITRAJE}

A efectos de lograr el objetivo principal del presente artículo, es de señalar que el principio de la autonomía de la voluntad contractual permite a las partes de una relación negocial el recurrir al arbitraje, por su propia iniciativa a través de un pacto arbitral o una cláusula compromisoria, en la búsqueda y practica de soluciones más efectivas y ágiles a sus controversias, previo al uso y configuración de medidas acaloradas como la terminación anticipada de la relación contractual, el incumplimiento del contrato y/o la resolución del mismo.

El principio de la autonomía de la voluntad contractual se materializa gracias al principio de la divisibilidad en el cumplimiento de todos los requisitos esenciales para la validez de este tipo de cláusulas y del principio de la universalidad mediante la estipulación expresa del consentimiento de las partes en recurrir al arbitraje, con el propósito de buscar soluciones más efectivas y especializadas que restablezcan el equilibrio contractual entre las partes. Pues:

"(...) bistóricamente podemos sostener que los origines de la justicia arbitral se confunden con los albores de la bumanidad. La necesidad de restablecer el equilibrio ante el agravio ajeno, o la agresión inmerecida, es decir el trabajo de impartir justicia, se confió primero a particulares destacados por su prudencia y sabiduría y, sólo tiempos después, fue asignado a la organización estatal como realizador del Derecho a través de la Administración de justicia (... $)^{\prime 2}$.

La fuerza vinculante del Principio de la autonomía de la voluntad contractual no es novedosa en nuestro ordenamiento jurídico civil. No es un secreto el afirmar que dicho Principio siempre ha estado inmerso y presente en nuestro Código Civil ${ }^{3}$ como base fundamental del negocio jurídico, el cual suele perfeccionarse como un Contrato. Sin este Principio, en términos de cumplimiento de requisitos esenciales, naturales y accidentales, los negocios jurídicos no podrían nacer a las relaciones jurídicas como contrato, dado que la perfección de aquel puede considerarse como una "(...) Noción perteneciente a la teoría o doctrina general del derecho, que bace parte de la dinámica jurídica, fundamental en él y para el derecho privado, y en tal sentido comparable apenas con las nociones de derecho subjetivo y acto ilícito; en fin, motor del tráfico jurídico, sin cuya presencia no es imaginable el desarrollo de sociedad alguna (...)"4.

2 ERnesto Gamboa Morales. El arbitraje en equidad. Bogotá: Academia Colombiana de Jurisprudencia, (2003): 6-7.

3 Colombia. Código de Civil. Ley 84 de 1873 (26 de mayo). Diario Oficial n. ${ }^{\circ} 2.867$ de 31 de mayo de 1873). Bogotá. Artículo 1602

4 Cfr. Fernando Hinestrosa Óp. cit, p. 1 
El derecho arbitral ha tomado gran fuerza en los últimos años gracias al Principio de la autonomía de la voluntad contractual. Configurándose entonces, este principio como esencial en las relaciones comerciales y civiles de la actualidad, ya que, sin aquel, no se podría materializar el consentimiento, la capacidad y la manifestación de la voluntad de los contrayentes en el perfeccionamiento de un negocio jurídico. Siendo entonces la principal consecuencia de la ausencia de dicho principio, el no nacimiento a la vida jurídica de aquellos.

El supuesto de tiempo antes mencionado, respecto al auge del arbitraje como medio de resolución de conflictos en las relaciones contractuales cuantiosas en uso del Principio de la autonomía de la voluntad contractual, también se debe a la reciente modificación de la Ley 446 de 1998 a través de la Ley 1563 de 2012 la cual, a partir de la fecha, instituye en Colombia el Estatuto de Arbitraje Nacional e Internacional el cual incorpora un cuerpo normativo nacional que proporciona al proceso arbitral celeridad, eficacia, especialidad y economía procesal como ventajas adicionales del arbitraje como justicia privada.

De allí que el multicitado Principio tenga como propósito el servir en las relaciones negociales y contractuales como una herramienta fundamental y clave para la activación de los mecanismos alternativos de resolución de conflictos, toda vez que gracias a la libertad contractual que poseen las partes para determinar sus acuerdos como ley para ellas en un contrato, es que las mismas pueden acceder a solucionar sus controversias en el arbitraje sin tener que comparecer obligatoriamente a la jurisdicción ordinaria.

\section{EL ARBITRAJE NACIONAL E INTERNACIONAL}

Por lo expuesto, "es menester precisar que todos los arbitrajes son "nacionales" en el sentido de que se llevan a cabo en un determinado foro, o sede del arbitraje, y que se deben someter a las normas imperantes en este. No obstante, las normativas que regulan el arbitraje en los diferentes Estados pueden divergir, en el sentido de que otorgan un tratamiento diferencial, dependiendo si el arbitraje que se adelanta en ese lugar enmarca o no dentro de los criterios de internacionalidad que su propia ley prevé. Estos ordenamientos, que consagran regulaciones diversas en uno y otro caso se denominan dualistas".

Considerándose entonces nuestro sistema de arbitraje como dualista, ya que permite a las partes parte de una controversia para su solución, el concurrir a un arbitraje nacional como internacional para la resolución de sus diferencias, siempre y cuando se respeten los siguientes límites:

A, En el caso del arbitraje Nacional, el límite para la resolución de controversias son las disposiciones contenidas en el artículo cincuenta y ocho (58) de la Ley 1563 de 2012, las cuales se representan en la siguiente gráfica: 
"En los arbitrajes en que no sea parte el Estado o alguna de sus entidades, los particulares podrán acordar las reglas de procedimiento a seguir, directamente o por referencia a las de un centro de $\operatorname{arbitraje}(\ldots)^{\prime \prime}$

\section{PRINCIPIO DE LA AUTONOMÍA DE LA VOLUNTAD} CONTRACTUAL

“(...) respetando, en todo caso los principios constitucionales que integran el debido proceso, el derecho de defensa y la igualdad de las partes. (...)"

ORDEN PÚBLICO, PRINCIPIO PACTA SUNT

SERVANDA CUMPLIMIENTO DEL ORDENAMIENTO JURÍDICO QUE DIRIMIE LA CONTROVERSIA

“(...) en el evento en que las partes no establecieren reglas o el centro seleccionado para adelantar el trámite no tuviere reglamento de procedimientos debidamente aprobados, se aplicarán las reglas establecidas para cada caso en la presente ley"

B. Mientras que, en el Arbitraje Internacional el límite es impuesto por voluntad de las partes, quienes configuran por libre elección, las reglas y/o disposiciones más pertinentes para dirimir sus controversias. Pudiéndose entonces destacar el arbitraje internacional como:

"(... la jurisdicción natural del comercio internacional. Esta frase se ba banalizado completamente en nuestros días. Parte de este fenómeno que se debe a la asociación que se ba becho entre los conceptos de arbitraje internacional y especialidad, imparcialidad, celeridad, economía, etc $(\ldots)^{\prime \prime}$.

La anterior precisión, tiene como propósito el distinguir e individualizar entre un arbitraje nacional e internacional, entendiendo entonces que en el primero el limite a la autonomía a la voluntad contractual está expresamente consagrado en la Ley, mientras que en el segundo, tal limite se constituye por voluntad de las partes en relación directa con el fondo de la controversia y algunos otros criterios directas para su individualización.

\section{LAS VENTAJAS DEL ARBITRAJE EN COLOMBIA}

Conforme a la doctrina clásica del Derecho Arbitral, el arbitraje nacional e internacional, en comparación a la justicia ordinaria, ofrece las siguientes ventajas en favor de las partes intervinientes en una controversia contractual por medio de una cláusula compromisoria y/o pacto arbitral, cuando se constituye el denominado Tribunal Arbitral.

Las ventajas son relevantes para grandes empresarios y comerciantes en sus acuerdos contractuales, en el entendido que ahorran dinero y esfuerzos en la

5 DiANA CORREA ANGEL. «El reconocimiento y la ejecución de un laudo internacional anulado en el país de la sede arbitral». e - Mercatoria, vol. 7, n. ${ }^{\circ} 2$ (2008) (2008): 2-8. 
resolución de sus controversias, de una manera civilizada, ágil y en igualdad de condiciones tantos sustanciales y formales; tal como podría suceder en un proceso de conocimiento de la jurisdicción ordinaria.

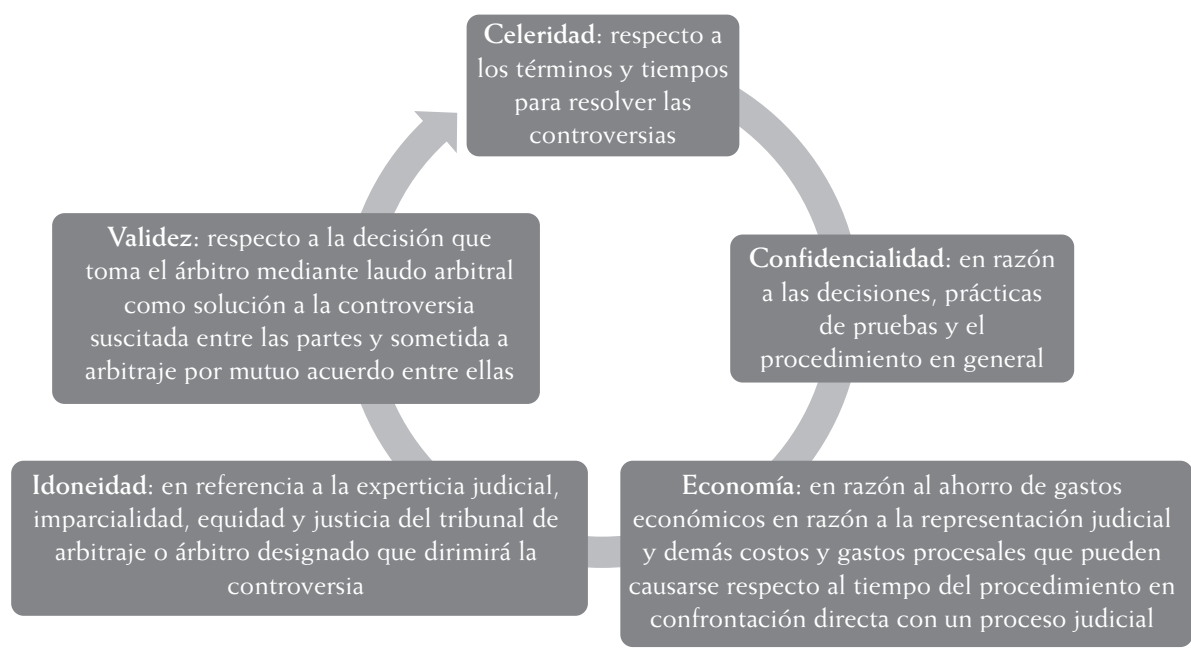

\section{EL RECONOCIMIENTO DEL DERECHO ARBITRAL EN EL ESTADO COLOMBIANO}

Es de señalar que el arbitraje nacional se define por disposición directa del artículo cincuenta y ocho (58 de la Ley 1563 de 2012, como un negocio jurídico en virtud del cual las partes de un contrato se someten y obligan a solucionar sus controversias presentes, pasadas o futuras ante un tribunal arbitral, como un mecanismo alternativo para la resolución de conflictos por intermedio del principio de la autonomía de la voluntad contractual, en reconocimiento de una justicia privada establecida por el Estado colombiano a través de la Constitución Política, y demás disposiciones particulares del ordenamiento jurídico local.

El reconocimiento del Arbitraje como mecanismo alternativo de relación de conflictos no solo se materializa en el Estatuto nacional e internacional de arbitraje, sino también en la protección general al derecho fundamental al debido proceso concebida el artículo veintinueve $(29)^{6}$ de la Constitución Política y en el reconocimiento del arbitraje como jurisdicción privada propia, autónoma y particular, en la cual un árbitro o tribunal arbitral imparte justicia, gracias a la voluntad de los interesados que acuden a él, mediante un pacto

6 Colombia. Constitución Política. Gaceta Constitucional, n. ${ }^{\circ} 116$ de 20 de julio de 1991. Bogotá. Artículo 29. 
arbitral o clausula Compromisoria, tal como lo estipula el artículo ciento dieciséis $(116)^{7}$ de la Constitución Política. Representándose entonces, dicha materialización así:

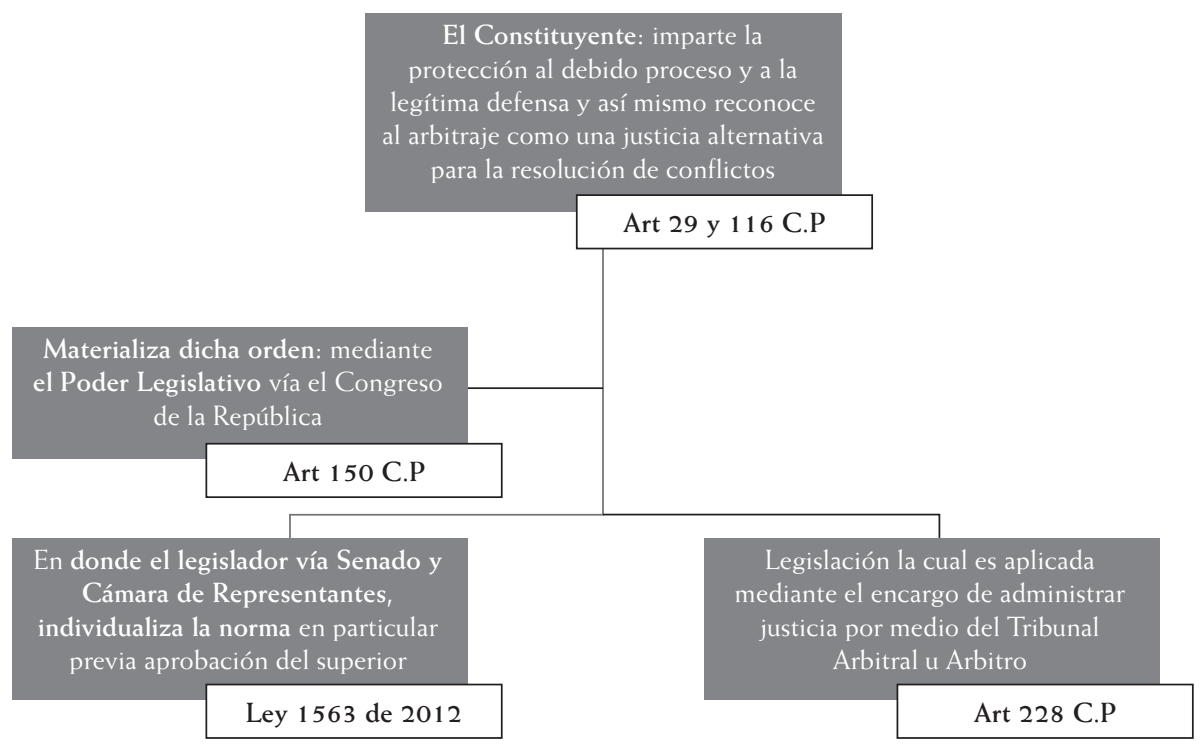

La anterior representación normativa, propia de la Teoría General del Derecho, posee una gran incidencia en el derecho arbitral nacional e internacional, ya que, a través de dicha protección otorgada por la justicia estatal de manera general, se individualizan las reglas y parámetros generales del arbitraje en Colombia, pues "(...) mientras la producción jurídica es expresión de un poder (originario o derivado), la ejecución revela el cumplimiento de un deber. Una norma que le atribuye a una persona o a un órgano el poder de dictar normas jurídicas impone al mismo tiempo, a otra persona, el deber de obedecerlas (... $)^{\prime \prime}$.

Normas que se manifiestan en los contratos, vía la denominada cláusula compromisoria y el denominado pacto arbitral, los cuales conjuntamente tienen como objeto principal el ser un negocio jurídico, el cual, para el conocimiento y la resolución de las controversias mediante arbitraje, tienen como principal efecto, la renuncia de las partes a hacer valer sus pretensiones y resolver sus controversias en la jurisdicción ordinaria9 .

7 Colombia. Constitución Política. Gaceta Constituciona, n. ${ }^{\circ} 116$ de 20 de julio de 1991. Bogotá. Artículo 116.

8 Colombia. Constitución Política. Gaceta Constitucional, n. ${ }^{\circ} 116$ de 20 de julio de 1991 Bogotá. Artículo 116.

9 NorberTo. BobbiO. Teoría general del derecho. 5. a ed. Legis. Bogotá: Legis, (2016): 157 
Para tal fin, se debe entender entonces la cláusula compromisoria ${ }^{10} \mathrm{como}$ el convenio mediante el cual las partes contratantes acuerdan solucionar por medio del arbitraje las controversias presentes o futuras de su relación contractual y, por otro lado, debe definirse el pacto arbitral ${ }^{11}$ como el acuerdo mediante el cual las partes también convienen someter sus controversias al arbitraje con o sin un vínculo contractual, aun cuando el asunto ya haya sido conocido por la justicia ordinaria siempre y cuando dicha controversia no haya sido resuelta por el juez ordinario vía sentencia judicial, siendo entonces:

"(... el pacto arbitral como fuente exclusiva del arbitraje, puede adoptar la forma de una clausula compromisoria o de un compromiso. La cláusula compromisoria se caracteriza por celebrarse antes de que surja la controversia que se defiere a conocimiento de árbitros $y$, en todos los casos, se refiere solamente a asuntos contractuales; por el contrario, el compromiso se celebra una vez existen las controversias respectivas, las cuales pueden ser tanto de orden contractual como extracontractual $(\ldots)^{\prime \prime 12}$

\section{LOS LAUDOS ARBITRALES COMO DECISIONES AUTÓNOMAS EN COLOMBIA}

La decisión proferida por el árbitro, denominada como laudo arbitral, puede ser en equidad cuando "(...) los árbitros deciden según el sentido común y la equidad $(\ldots)^{\prime 13}$ y en derecho cuando "(...) los arbitros fundamentan su decision en el derecho positivo vigente (... $)^{\prime \prime 14}$. En este punto, se debe señalar que el árbitro que profiere una decisión en derecho debe ser abogado inscrito ante la respectiva autoridad competente, sin que esa misma regla se deba aplicar al arbitraje en equidad.

En razón a la diferencia que existe entre el laudo arbitral en derecho con el que se pueda expedir en equidad, se debe resaltar que estos, en cualquier caso, pueden tener la naturaleza de arbitraje técnico, esto es: "(...) cuando los árbitros pronuncien su fallo en razón de sus específicos conocimientos en una determinada, ciencia, arte u oficio $(\ldots)^{\prime \prime 15}$. Cabe señalar que la mayoría de los laudos arbitrales en derecho emitidos por los tribunales de arbitraje en Colombia tienen un componente de equidad y de conocimientos técnicos y nuestra legislación, la doctrina y la jurisprudencia, como la expedida por la Corte Constitucional,

10 Colombia. Estatuto de Arbitraje Nacional e Internacional y se dictan otras disposiciones. Ley 1563 de 2012. Diario Oficial n. ${ }^{\circ} 48.489$ de 12 de julio de 2012. Bogotá. Artículo 4.

11 Colombia. Estatuto de Arbitraje Nacional e Internacional y se dictan otras disposiciones. Ley 1563 de 2012. Diario Oficial n. ${ }^{\circ} 48.489$ de 12 de julio de 2012. Bogotá. Artículo 3.

12 Bejarano Guzman, Ramiro, Aida Patricia Hernàndez Silva, y Pablo Moreno Cruz. El Recurso de Anulación de los laudos Arbitrales. Bogotá: Universidad Externado de Colombia, 2019: 58

13 Gamboa Morales, Ernesto, Óp. cit, p. 1.

14 ERnesto Gamboa Morales, El arbitraje en equidad, Óp. cit, p. 1.

15 ERnesto Gamboa Morales, El arbitraje en equidad, Óp. cit, p. 1 
han aceptado con la misma fuerza ejecutoria los laudos arbitrales proferidos en equidad y/o técnicos de manera particular e individual.

De ahí que por lo antes expuesto, los laudos arbitrales en el Estado colombiano sean reconocidos como decisiones judiciales $y$, por ende, tengan la misma fuerza ejecutoria y de validez de una sentencia, como una consecuencia directa y propia del principio de la autonomía de la voluntad contractual en cabeza del tribunal arbitral.

\section{DEL RECURSO EXTRAORDINARIO DE ANULACIÓN Y REVISIÓN DE LOS LAUDOS ARBITRALES}

Sumado entonces a los tipos de laudos arbitrales reconocidos en el ordenamiento colombiano, es de destacar que aun cuando dichas decisiones y procedimientos gozan del principio de la autonomía de la voluntad contractual por disposición de la Constitución y de la Ley, dichas decisiones en todo caso están sujetas al control jurisdiccional de los tribunales judiciales, toda vez que en el evento en que no se garantice de manera sustancial o procedimental en la decisión del árbitro la garantía de los derechos fundamentales como el debido proceso y los deberes instituidos por el Estado, los interesados podrán acudir a la autoridad judicial con el fin de anular y/o revocar la decisión mediante el recurso extraordinario de anulación y revisión, según sea el caso, sin perjuicio, incluso, de instaurar una acción de tutela de conformidad con lo consagrado en el artículo 86 de la Constitución Política ${ }^{16}$, según se verá.

La interposición de recursos en contra de un laudo arbitral trae consigo y como efecto particular el debatir el derecho procedimental y formal de la controversia sometida a arbitraje como se ilustra a continuación:

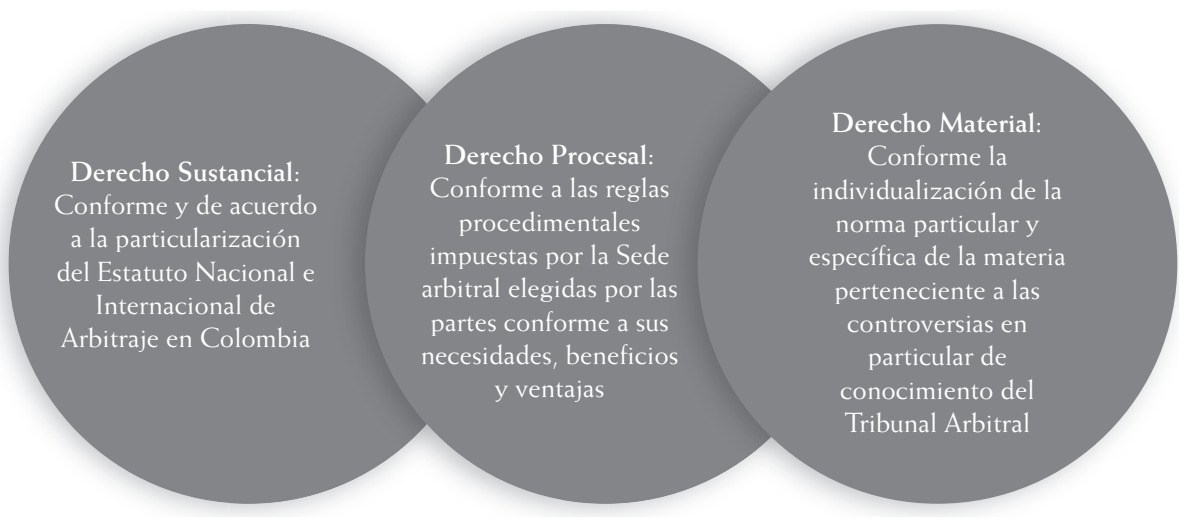

16 Colombia. Constitución Política. Gaceta Constitucional, n. ${ }^{\circ} 116$ de 20 de julio de 1991 Bogotá. Artículo 86. 
La intervención del control jurisdiccional, en todo caso, debe ser coherente y conforme a lo establecido expresamente en la Ley, de manera que no se desvirtué la autonomía del árbitro respecto de su decisión. Siendo competencia de la administración de justicia el resolver dichos recursos cuando no se cumplan los supuestos procesales a la hora de expedir un laudo arbitral y/o se afecta un derecho fundamental. Dicha intervención es posible gracias a los recursos extraordinarios de anulación y revisión, los cuales tienen el propósito de controvertir laudos arbitrales sobre aspectos formales.

Tales recursos están consagrados en la Ley 1563 de $2012^{[17]} \mathrm{e}$ implican que los tribunales judiciales, según sea el caso, puedan determinar la existencia de vicios ocasionados en el proceso arbitral. Es esencial destacar que el criterio tradicional de resolución de conflictos "lex superior derogat inferiori" ${ }^{18}$ se puede ver materializado mediante la intervención de los tribunales en cuanto a la revisión, existencia, configuración y procedencia de las causales expresas en la Ley tanto del recurso de anulación como del recurso de revisión, como bien lo establece los artículos cuarenta $(40)^{19}$ y cuarenta y cinco $(45)^{20}$ del Estatuto de Arbitraje Nacional e Internacional.

En ese orden de ideas y previo al estudio y conceptualización de la procedencia, fundamento y finalidad de dichos recursos, se hace necesario destacar que durante todo el proceso arbitral las partes en el debate procesal y probatorio tienen la posibilidad de incidir en la decisión final del árbitro que traerá como producto la solución a la controversia. Pues, el derecho arbitral también debe garantizar a las partes el libre derecho a la contradicción, a la legítima defensa y al debido proceso, respetando, en todo caso, las disposiciones especiales de la ley del foro que dirime la controversia en las siguientes etapas del procedimiento arbitral:

17 Colombia. Estatuto de Arbitraje Nacional e Internacional y se dictan otras disposiciones. Ley 1563 de 2012. Diario Oficial n. ${ }^{\circ} 48.489$ de 12 de julio de 2012. Bogotá.

18 Traduccion Libre. "(...) Per antinomie si intendono tutti quei casi in cui vi è incompatibilità tra due norme (Disposizione e norma) che disciplinano una medesima fattispecie, nel senso che l'applicazione dell'esclude l'applicazione dell'altra. La presenza di antinomie è fisiologica (e non patologica) all'interno di un qualsiasi ordinamento giuridico, in virtù della pluralità di fonti del diritto in esso esistenti. Da ciò discende che le antinomie sono un problema essenzialmente interpretativo (... )". Significado del principio "lex superior derogat inferiori" de la enciclopedia en línea Treccani, E. (15 de abril de 2019). Treccani.it/ enciclopedia. Obtenido de Treccani.it/enciclopedia: http://www.treccani.it/enciclopedia/ criteri-di-risoluzione-delle-antinomie/-

19 Colombia. Estatuto de Arbitraje Nacional e Internacional y se dictan otras disposiciones. Ley 1563 de 2012. Diario Oficial n. ${ }^{\circ} 48.489$ de 12 de julio de 2012. Bogotá. Artículo 40

20 Colombia. Estatuto de Arbitraje Nacional e Internacional y se dictan otras disposiciones. Ley 1563 de 2012. Diario Oficial n. ${ }^{\circ} 48.489$ de 12 de julio de 2012. Bogotá. Artículo 45 


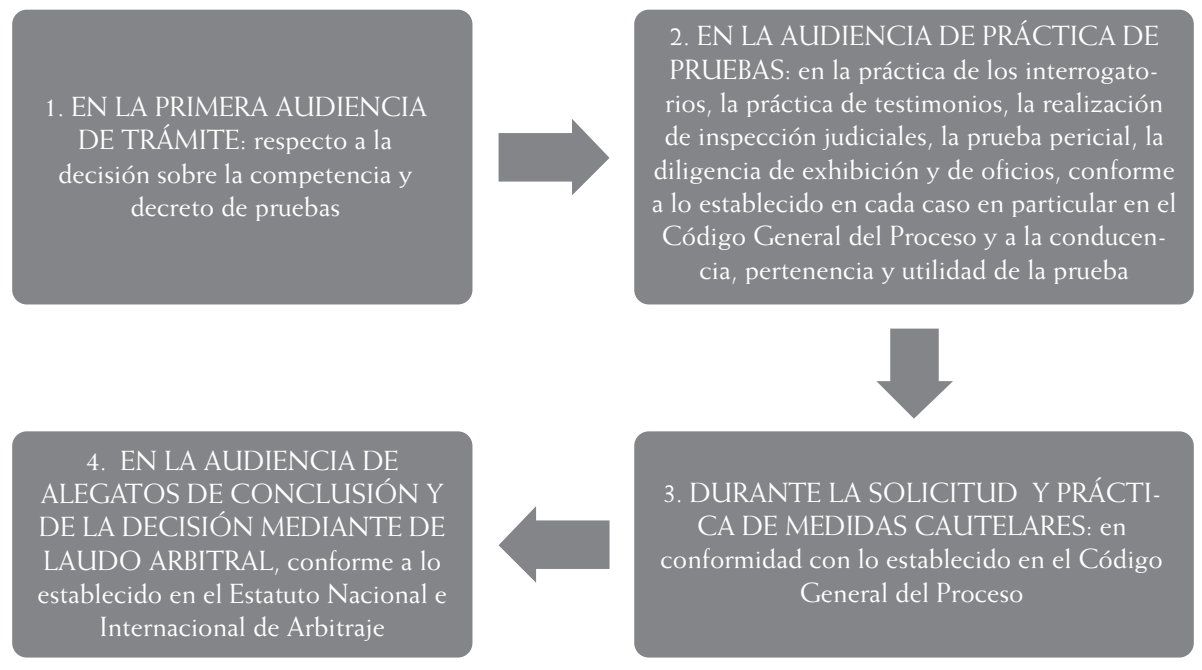

\section{A. Del recurso extraordinario de anulación PROCEDENTE CONTRA LOS LAUDOS ARBITRALES}

Por lo expuesto, es claro señalar entonces que el recurso de anulación tiene como propósito el enmendar los errores procedimentales que si hubiesen podido presentar en el procedimiento arbitral que no hayan sido puestos en conocimiento por el tribunal arbitral o este no los hubiese determinado dentro del desarrollo normal del procedimiento. Dicho recurso es de única instancia y solo procede por las causales expresas y consagradas en el Estatuto Nacional de Arbitraje Colombiano en su artículo cuarenta y uno (41), las cuales son:

"(...) 1. La inexistencia, invalidez absoluta o imposibilidad del pacto arbitral.

2. La caducidad de la acción, la falta de jurisdicción o de competencia.

3. No baberse constituido el tribunal en forma legal.

4. Estar el recurrente en alguno de los casos de indebida representación, o falta de notificación o emplazamiento, siempre que no se bubiere saneado la nulidad.

5. Haberse negado el decreto de una prueba pedida oportunamente o baberse dejado de practicar una prueba decretada, sin fundamento legal, siempre y cuando se bubiere alegado la omisión oportunamente mediante el recurso de reposición y aquella pudiera tener incidencia en la decisión. 6. Haberse proferido el laudo o la decisión sobre su aclaración, adición o corrección después del vencimiento del término fijado para el proceso arbitral.

7. Haberse fallado en conciencia o equidad, debiendo ser en derecho, siempre que esta circunstancia aparezca manifiesta en el laudo (...)".

Tales causales expresas, en todo caso, no dan pie conforme a su finalidad y propósito a la resurrección de las controversias materiales ya resueltas por 
el árbitro, sino a la revisión de las posibles fallas procedimentale ${ }^{21}$ entonces no detectadas durante el proceso arbitral tanto por el Tribunal que entonces dirimió la controversia como por las partes que acuden a él con el fin de hacer justicia sobre el particular.

Es de señalar que el objeto y la causa lícita son los defectos más comunes y aquellos que dan lugar a la procedencia del recurso de anulación, pues configuran el nacimiento de la nulidad del pacto arbitral. En el entendido, que el factor que configura el recurso de anulación será entonces aquel error procedimental que por su naturaleza no haya sido saneado o puesto en conocimiento durante el proceso arbitral al tribunal arbitral y/o árbitro, en los términos expresos de la ley procedimental de la sede y el tribunal arbitral que conoce la controversia que, para el caso colombiano, será Tribunal Judicial especializado y facultado en materia de la controversia, por disposición expresa de la Constitución Política y del Estatuto Nacional e Internacional de Arbitraje.

El propósito del recurso de anulación en todo caso debe ser interpretado estrictamente y conforme a lo estipulado por el legislador, ya que no es aceptable que los recurrentes, ante la pérdida de un proceso arbitral, sustenten y fundamenten el recurso de anulación con base al derecho material, fuente resolutoria de la controversia, a fin de reactivar un debate jurídico entonces ya resuelto por el árbitro en el proceso arbitral, pues:

"(... en principio el juez del recurso no puede examinar nuevamente el fondo de la decisión arbitral, porque su competencia es limitada, especifica y restringida, pues las causales consagradas en la Ley se refieren solo a errores de procedimiento, y no a errores sustanciales. A diferencia del recurso de apelación, el de anulación no da lugar entonces a una instancia adicional del proceso arbitral, por lo que únicamente puede estudiarse este tipo de errores. Sin embargo, cabe recordar que, si bien en reiteradas ocasiones las cortes precisaron que el recurso de anulación del laudos comprende solo vicios in procediendo, mas no in indicando, los límites entre unos y otros son cada vez más difíciles de establecer por que los análisis necesarios para definir la prosperidad de algunas causales no comportan únicamente al evaluación de simples vicios formales o de procedimiento, si no también $y$ de manera excepcional el análisis de errores sustanciales (... $)^{\prime \prime 22}$.

Entonces, como producto del agotamiento de todo el debate procesal y probatorio en el proceso arbitral se generará como principal resultado y constancia de la decisión, el Laudo arbitral, respecto del cual no será procedente el recurso de apelación por las razones antes expuestas, pues se entiende que en todas las instancias del procedimiento arbitral ya se agotó el derecho a la

21 Colombia. Estatuto de Arbitraje Nacional e Internacional y se dictan otras disposiciones. Ley 1563 de 2012. Diario Oficial n. ${ }^{\circ} 48.489$ de 12 de julio de 2012. Bogotá. Artículo 16

22 Ramiro, Bejarano Guzman, Aida Patricia Hernàndez Silva y Pablo Moreno Cruz. El Recurso de Anulación de los laudos Arbitrales. Bogotá: Universidad Externado de Colombia, 2019: 58. 
contradicción y a la legitima defensa pertenecientes al derecho fundamental del debido proceso. De allí que el legislador, a efectos de realizar un control de la decisión como consecuencia de la no procedencia del recurso de apelación, consagre "(...) que las partes no pueden voluntariamente excluir de la cláusula compromisoria la facultad que le asiste a las partes de interponer el recurso de anulación, ya que las normas procesales son de orden público y de obligatorio cumplimiento (... $)^{\prime 23}$.

\section{B. Del RECURSO EXTRAORDINARIO DE REVISIÓN PROCEDENTE CONTRA LOS LAUDOS ARBITRALES}

Como mecanismo de examen del recurso de anulación, el Estatuto de Arbitraje nacional e internacional colombiano prevé el recurso extraordinario de revisión, el cual tiene como propósito el validar el control jurisdiccional de la decisión anulable conforme a la ley procedimental utilizada en el proceso arbitral ${ }^{24}$ una vez el laudo se encuentre en firme. Razón por la cual, su procedencia se encaminará en las siguientes causales expresas del artículo trescientos cincuenta y cinco (355) del Código General del Proceso, así:

"(...) 1. Haberse encontrado después de pronunciada la sentencia documentos que babrían variado la decisión contenida en ella, y que el recurrente no pudo aportarlos al proceso por fuerza mayor o caso fortuito o por obra de la parte contraria.

2. Haberse declarado falsos por la justicia penal documentos. Que fueron decisivos para el pronunciamiento de la sentencia recurrida.

3. Haberse basado la sentencia en declaraciones de personas que fueron condenadas por falso testimonio en razón de ellas.

4. Haberse fundado la sentencia en dictamen de perito condenado penalmente por ilícitos cometidos en la producción de dicha prueba.

5. Haberse dictado sentencia penal que declare que bubo violencia o cobecho en el pronunciamiento de la sentencia recurrida.

6. Haber existido colusión u otra maniobra fraudulenta de las partes en el proceso en que se dictó la sentencia, aunque no baya sido objeto de investigación penal, siempre que baya causado perjuicios al recurrente.

7. Estar el recurrente en alguno de los casos de indebida representación o falta de notificación o emplazamiento, siempre que no baya sido saneada la nulidad.

8. Existir nulidad originada en la sentencia que puso fin al proceso y que no era susceptible de recurso.

9. Ser la sentencia contraria a otra anterior que constituy a cosa juzgada entre las partes del proceso en que aquella fue dictada, siempre que el recurrente no bubiera podido

23 Ramiro, Bejarano Guzman, Aida Patricia Hernàndez Silva y Pablo Moreno Cruz, Óp. cit., p. 26.

24 Colombia. Código General del Proceso. Ley 1564 de 2012. Diario Oficial n. ${ }^{\circ} 48.489$ de 12 de julio de 2012. Bogotá. Artículo 354. 
alegar la excepción en el segundo proceso por babérsele designado curador ad lítem y baber ignorado la existencia de dicho proceso. Sin embargo, no babrá lugar a revisión cuando en el segundo proceso se propuso la excepción de cosa juzgada y fue rechazada. $(\ldots)^{\prime \prime}$.

Teniendo entonces, como principales propósitos el recurso de revisión los expresados en la siguiente gráfica:

1. El invalidar la providencia realizada objeto de vulneración y proceder a proferir y dictar sentencia que sustituya dicha decisión a fin de garantizar todos los derechos y deberes proclamados por el Estado
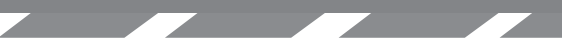

2. Reenviar la providencia revisada producto de la anteposición y procedencia de dicho recurso al despacho de origen, con el propósito de que el despacho de origen es decir el tribunal arbitral vuelva a proferir sentencia sobre el fondo del asunto objeto de revisión, sin perjuicio de las demás acciones que pueden prosperar para la revocatoria del fallo (tutela), haciendo claridad de que esta posibilidad solo es procedente, cuando el recurso de revisión verse sobre sentencia que resolvió el recurso de anulación en contra del laudo, de allí que cuando se establecieran las nociones generales de este recurso se hiciera énfasis a la íntima conexidad de este recurso de anulación.

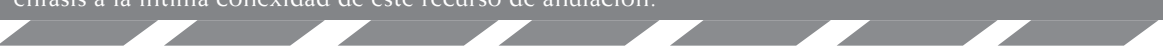

3. Declarar la nalidad del proceso arbitral en los eventos en que dicho actuar sea contrario a la ley sustancial, procesal, material.

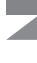

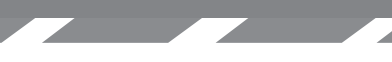

El concepto y la definición de los recursos extraordinarios de revisión y anulación en el ordenamiento jurídico colombiano, adicional a lo anterior están sometidos a un control jurisdiccional realizado por los altos tribunales administrativos tal y como lo ha reiterado la Corte Constitucional al señalar mediante la Sentencia C-1436 de 2000 que: "los árbitros no tienen competencia para pronunciarse sobre los actos administrativos dictados por la administración en desarrollo de sus poderes excepcionales" 25 .

Sumado a ello, también se ha señalado que contra las decisiones arbitrales es procedente el Control Constitucional vía la acción de tutela cuando se considere vulnerado algún derecho fundamental en el proceso arbitral o con ocasión a las providencias que resuelven el recurso extraordinario de anulación y/o de revisión antes explicados.

\section{EL CONTROL JURISDICCIONAL CONSTITUCIONAL DE LOS LAUDOS ARBITRALES}

La jurisprudencia de la Corte Constitucional de Colombia se ha pronunciado en diferentes ocasiones sobre el control judicial de los laudos arbitrales.

25 Ramiro Bejarano Guzman, Aida Patricia Hernàndez Silva y Pablo Moreno Cruz. Óp. cit., p. 65. 
Ha señalado que las providencias judiciales que materializan aquel control judicial son susceptibles de vulnerar derechos fundamentales, de allí que sea procedente la acción de tutela en contra de dichas providencias.

A continuación, se procederá a explicar: (i) los fundamentos de la procedencia de la acción de tutela para controvertir una providencia judicial ${ }_{;}$(ii) los requisitos generales de procedencia de una acción de tutela para controvertir una providencia judicial ${ }_{i}$ (iii) la procedencia de la acción constitucional para cuestionar un laudo arbitral y (iv) los defectos que pueden contener una providencia que realiza el control judicial sobre un laudo arbitral. Con tal fin, se acudirá a las explicaciones desarrolladas en la sentencia SU-556 de 2016.

\section{A. Fundamentos de la PROCEDEnCIA De La ACCión DE TUTELA PARA CONTROVERTIR UNA PROVIDENCIA JUDICIAL}

La procedencia de la acción de tutela para cuestionar una providencia judicial no ha sido ajena a las discrepancias suscitadas al interior de la comunidad jurídica colombiana, siendo esta última, aquella integrada por la academia con los profesores de las facultades de derecho y sus estudiantes, los profesionales del derecho y la rama del poder judicial con sus organismos de cierre (Corte Suprema de Justicia, Consejo de Estado y Corte Constitucional). Tales discrepancias han generado, incluso, un impacto en la opinión pública, gracias, entre otras cosas: (i) al carácter vinculante, hoy día, de los precedentes jurisprudenciales (muy propio del sistema del common law (anglosajón), frente a la tradición romano-germánica (continental) que predomina en el sistema jurídico colombiano, y (ii) al denominado choque de trenes.

Con el objetivo de desarrollar lo anterior, se describirán los fundamentos jurídicos de la acción tutela como mecanismo de control constitucional excepcionalísimo de las providencias judiciales inmersos en la Constitución Política de 1991, el Decreto Ley 2591 de 1991, los instrumentos internacionales y en la jurisprudencia de la Corte Constitucional. Con tal fin, se debe resaltar que a pesar de que Colombia cuenta con una "nueva" Carta Fundamental con carácter normativo de acuerdo con su artículo cuarto $\left(4^{\circ}\right)^{26}$, en varios sectores de la comunidad jurídica persiste el afán por la interpretación formalista del Derecho. En palabras del profesor Manuel Fernando Quinche, un arraigo "por la lectura religiosa del derecho" ${ }^{\prime 27}$, como si se tratase de la derogada Constitución de 1886, que se caracterizaba por ordenar a ultranza el obedecimiento de la ley. Lo anterior ha generado contradicciones con el Estado social de Derecho

26 Colombia. Constitución Política. Gaceta Constitucional n. ${ }^{\circ} 116$ de 20 de julio de 1991. Bogotá. Artículo 4.

27 Manuel Fernando, Quinche Ramírez. Vías de becho. Acción de tutela contra providencias. Bogota: Univesidad del Rosario , 2007. 
de la Carta vigente que busca la materialización del principio de igualdad como mandato de optimización ${ }^{28}$, según se verá.

De otro lado, el artículo 86 de la Constitución Política de Colombia señala que toda persona puede acudir a la acción de tutela para reclamar ante los jueces la protección inmediata de sus derechos fundamentales cuando estos hubiesen sido vulnerados o amenazados por la acción u omisión de cualquier autoridad pública, incluyéndose, desde luego, a los jueces y tribunales cuyas actuaciones se reflejan en las providencias judiciales ${ }^{29}$.

Pese a la claridad gramatical de la norma, en diversos sectores se discutía sobre quiénes eran los sujetos a los hacía referencia el Constituyente cuando señaló que la acción de tutela procedía ante la afectación proveniente de cualquier autoridad pública. Tal asunto fue el inicio de la discusión que se ha venido evidenciando a través de la jurisprudencia constitucional colombiana sobre el tema presentado.

La Constitución Política de 1991, el Pacto Internacional de Derechos Civiles y Políticos, la Convención Americana sobre Derechos Humanos y la misma jurisprudencia de la Corte Constitucional contienen los fundamentos jurídicos sobre la procedencia de la acción de tutela ante la vulneración de los derechos fundamentales a través de actuaciones judiciales o mediante las "vías de becho"

Atendiendo el denominado "bloque de constitucionalidad", previsto en el artículo noventa y tres (93) de la Carta ${ }^{31}$, tenemos que el Pacto Internacional de Derechos Civiles y Políticos y la Convención Americana sobre Derechos Humanos prevén la existencia de un recurso para que sus asociados aleguen la vulneración de los derechos fundamentales aun cuando provenga de personas que actúen en ejercicio de funciones oficiales.

En el caso del Pacto Internacional de Derechos Civiles y Políticos ${ }^{32}$, su artículo segundo $\left(2^{\circ}\right)$ dispone que [ $\mathrm{t}$ ]oda persona cuyos derechos o libertades reconocidos en el presente Pacto bayan sido violados podrá interponer un recurso efectivo, aun cuando tal violación bubiera sido cometida por personas que actuaban en ejercicio de sus funciones oficiales $(\ldots)^{\prime \prime}$. Por su parte, el artículo veinticinco (25) de la Convención establece que:

28 Robert, Alexy. Teoría de los Derechos Fundamentales. Madrid: Centro de Estudios Constitucionales, 1993.

29 Colombia. Constitución Política. Gaceta Constitucional n. ${ }^{\circ} 116$ de 20 de julio de 1991. Bogotá. Artículo 86

30 Colombia. Corte Constitucional de Colombia. Sentencia T-774 de 2004. 13 de agosto de 2004, magistrado Manuel José Cepeda Espinosa. Disponible en: http://www.corteconstitucional.gov.co/RELATORIA/2004/T-774-04.htm.

31 Colombia. Constitución Política. Gaceta Constitucional n. ${ }^{\circ} 116$ de 20 de julio de 1991 Bogotá. Artículo 93

32 Pacto Internacional de Derechos Civiles y Políticos. Adoptado y abierto a la firma, ratificación y adhesión por la Asamblea General en su resolución 2200 A (XXI), de 16 de diciembre de 1966 Entrada en vigor: 23 de marzo de 1976, de conformidad con el artículo 49 Lista de los Estados que han ratificado el pacto, dentro del cual se encuentra Colombia. 
"Toda persona tiene derecho a un recurso sencillo y rápido o a cualquier otro recurso efectivo ante los jueces o tribunales competentes, que la ampare contra actos que violen sus derechos fundamentales reconocidos por la Constitución, la ley o la presente Convención, aun cuando tal violación sea cometida por personas que actúen en ejercicio de sus funciones oficiales (...)".

\section{B. PROCEDENCIA DE LA ACCión DE TUTELA PARA CONTROVERTIR UNA PROVIDENCIA JUDICIAL}

El tribunal constitucional colombiano ha venido señalando que la acción de tutela contra providencias judiciales, como regla general no procede. Con tal fin, ha presentado diversas razones, entre ellas, porque: (i) aquellas providencias son fruto de reconocimiento y de realización de derechos fundamentales por parte de funcionarios que están preparados para $\mathrm{ello}_{i}$ (ii) las sentencias que resuelven las controversias revisten del valor de la cosa juzgada y atienden el principio de seguridad jurídica y; (iii) la jurisdicción le asiste autonomía e independencia conforme a un régimen democrático.

Pese a lo anterior, la misma Corporación ha indicado que la acción de tutela encaminada a cuestionar providencias judiciales procede excepcionalmente, siempre que se cumplan unos rigurosos requisitos de carácter general. Según la sentencia SU- 400 de $2012^{33}$, una acción de tutela que tenga tal propósito debe atender los siguientes requisitos generales:

Primero. Relevancia constitucional. Se ha señalado que el juez o tribunal que conozca de la acción de tutela debe establecer la importancia constitucional que recae sobre la misma y evitar involucrarse en asuntos cuya competencia recae en otras jurisdicciones.

Segundo. Subsidiariedad. Conlleva el agotamiento de todos los medios -ordinarios y extraordinarios- de defensa judicial al alcance, salvo que se trate de evitar un perjuicio irremediable. Tal requisito implica que el actor haya acudido a todos los mecanismos judiciales que el legislador estableció para reclamar la garantía de sus derechos y, con ello, evitar que la acción de tutela se convierta en un mecanismo que vacíe las competencias de las demás autoridades judiciales.

Tercero. Inmediatez. La acción constitucional debe interponerse dentro de un término razonable y proporcionado, el cual se cuenta desde la expedición de la providencia que se pretende cuestionar. De no ser así, los principios constitucionales de cosa juzgada y seguridad jurídica quedarían en duda, pues de prolongarse en el tiempo la presentación de una acción de tutela conllevaría una incertidumbre sobre los fallos judiciales que se buscan evitar.

33 Colombia, Corte Constitucional de Colombia. Sentencia SU-400 de 2012. 31 de mayo de 2012, magistrada Adriana María Guillén Arango. Disponible en: http://www.corteconstitucional.gov.co/relatoria/2012/su400-12.htm. 
Cuarto. Irregularidad procesal. Se trata de un requisito alternativo que busca establecer que la providencia judicial cuestionada sea producto de una irregularidad procesal lo suficientemente determinante o decisiva en aquella y que, al mismo tiempo, tenga el alcance de afectar los derechos fundamentales del actor.

Quinto. Presentación del caso. La jurisprudencia constitucional ha indicado que el interesado debe identificar los hechos que generaron la vulneración, así como los derechos presuntamente desconocidos. Del mismo modo, el requisito exige que tal desconocimiento haya sido alegado en el respectivo proceso judicial en la medida en que hubiese sido posible.

Sexto. No se puede tratar de una sentencia de tutela. La causal de procedencia implica que la interposición de acción de tutela no puede prolongar indefinidamente la resolución de un caso que involucre la protección de los derechos fundamentales. De allí que las sentencias que se tomen en el marco de una acción de tutela se tornen definitivas, aunado a que tales providencias son sometidas a un riguroso proceso de estudio en la Corte Constitucional para su eventual revisión.

Es de destacar que la sentencia SU-400 de 2012 también expone los defectos o las causales específicas de procedibilidad que se deben exponer en una acción de tutela que pretenda controvertir una providencia judicial. Una vez se establezca el cumplimiento de los requisitos de carácter general, se debe acreditar que la providencia adolece de uno o varios de los defectos o causales que se describen a continuación:

- Defecto orgánico. Se presenta cuando el juez que profirió la providencia judicial reprochada carezca de competencia para ello.

- Defecto procedimental absoluto. Se genera cuando el juez que profirió la providencia actuó desconociendo el procedimiento respectivo establecido por el legislador.

- Defecto fáctico. La causal se materializa en el momento en que el juez toma su decisión sin el apropiado sustento probatorio.

- Defecto material o sustantivo. Se presenta cuando el fallo judicial es producto de la aplicación de normas inexistentes, inconstitucionales, esto es, a partir de normas inaplicables para el caso concreto.

- Error inducido. El defecto que se genera cuando la decisión judicial es producto de un engaño por parte de terceros.

- Decisión sin motivación. La causal conlleva que la sentencia judicial no da cuenta de los fundamentos fácticos y jurídicos que motivaron la decisión.

- Desconocimiento del precedente. Una providencia judicial contiene tal defecto cuando, a pesar de existir un pronunciamiento de la Corte Constitucional que define el alcance de un derecho fundamental, se produce 
aplicando una ley que limita dicho pronunciamiento que, sea del paso decir, tiene carácter vinculante.

- Violación directa de la Constitución. En esencia, el defecto se materializa cuando el juez encargado de proferir la decisión desarrolla dicha labor desconociendo los postulados de la Constitución.

\section{PROCEDENCIA DE LA ACCIÓN CONSTITUCIONAL PARA CUESTIONAR UN LAUDO ARBITRAL}

La Corte Constitucional se ha mostrado cautelosa frente a la procedencia de una acción de tutela que pretenda controvertir una decisión judicial relacionada con un laudo arbitral. Por su parte, la academia ha mostrado un interés creciente por estudiar la jurisprudencia de la Corte respecto de la procedencia del mecanismo de amparo colombiano contra los laudos arbitrales $y$, a partir de ello, plantear reflexiones que surgen con ocasión a la experiencia profesional desde la esfera de la justicia arbitral, administrativa y constitucional ${ }^{14}$.

Otros trabajos se han encargado de describir los pronunciamientos del Tribunal constitucional colombiano sobre la procedencia de la acción de tutela contra decisiones arbitrales cuando se configura lo que se denominaba con anterioridad como vías de hecho, al momento de ejercer el control constitucional abstracto y concreto ${ }^{35}$.

El asunto también ha sido objeto de estudio a partir de las experiencias de países latinoamericanos. En "El Arbitraje y los Ordenamientos Jurídicos en Latinoamérica: Un Estudio sobre Formalización y Judicialización ${ }^{\prime \prime 3}$ se considera que el arbitraje presenta una problemática regional con ocasión a su constitucionalización a través de jurisprudencias de diferentes países que promueven una cultura desfavorable a la liberación de dicho mecanismo alternativo para la resolución de conflictos.

En dicho texto se concluye que uno de los factores que promueve la excesiva judicialización y formalización del arbitraje es su constitucionalización debido a mecanismos como la acción de tutela o de amparo que buscan la protección de las garantías y los derechos fundamentales que se puedan vulnerar mediante una decisión arbitral. Se ha llegado a concluir que con ocasión a los mecanismos judiciales que no son inherentes a la naturaleza del arbitraje se generan visos de intervencionismo. Veamos:

34 GabRiel, De VeGa PinZÓn. «La acción de tutela contra laudos arbitrales. Breve análisis a partir de la jurisprudencia constitucional». Revista de la Academia Colombiana de Jurisprudencia. Arbitraje, conciliación, amigable composición y doctrina, 2018: 43-64.

35 Jorge EnRIQUe, IbANEZ NajAR. La acción de tutela contra laudos arbitrales. Bogota: Pontificia Universidad Javeriana, 2009.

36 Pablo, Rey Vallejo. «El Arbitraje y los Ordenamientos Jurídicos en Latinoamérica: un estudio sobre formalización y judicialización. Vniversitas(126), 199-237». Vniversitas, 2013: 199-237. 
"(...) la regulación del arbitraje en varios de los casos estudiados dista de ser autosuficiente ya que en la práctica se ba permitido que a través de mecanismos judiciales, que no son inberentes a la naturaleza de la figura, se abra la puerta para la intervención judicial en un plano que, lejos de ser colaborativo o de apoyo a los tribunales arbitrales, adquiere visos de intervencionismo" ${ }^{137}$.

En el caso colombiano, existen posiciones críticas sobre la procedencia de la tutela contra un laudo arbitral. Es así que en el artículo científico: "Tutela contra laudo arbitral: una controversia $\sin$ finn $^{\prime \prime 3}$, se hace una descripción sobre las posturas que están en su favor o en su contra. Para ello, se describen algunas consideraciones al respecto desde perspectivas: (i) económicas, tras pensar que el tema aumenta los costos de transacción al extender el proceso arbitral con ocasión a la presentación de una acción de tutela en su contra y (ii) judicial, ante la afectación al principio de la seguridad jurídica si se tiene en cuenta que los jueces de tutela no son los conocedores naturales del arbitraje; la eventual congestión judicial; y la falta de legitimación que tendrían los árbitros al momento de ser accionados en el marco de una acción de tutela, pues su competencia jurisdiccional es transitoria según el principio de temporalidad en el arbitraje, entre otros aspectos.

En el artículo científico citado se concluye que la procedencia de la acción de tutela contra los laudos arbitrales no riñe con los postulados jurídicos colombianos pues, contrario a ello, concreta y materializa las garantías de los derechos fundamentales de las personas que acuden a la administración de justicia tras considerar afectados sus derechos constitucionales con ocasión a un laudo arbitral ${ }^{39}$.

Por otro lado, se logra identificar, a partir de una investigación sobre la línea jurisprudencial de la Corte Constitucional sobre el tema objeto de análisis, que el control judicial para determinar la procedencia de una acción de tutela para controvertir una decisión judicial relacionada con un laudo arbitral es más estricto. El texto: El Derecho de los Jueces plantea una técnica para investigar líneas jurisprudenciales ${ }^{40}$. Dada la pertinencia de la obra en la que se explican técnicas para analizar y determinar líneas jurisprudenciales, se acudirá a dicho texto para ilustrar las determinaciones de la Corte Constitucional frente al asunto que hoy es materia de estudio.

Como primera medida se acudirá a la Sentencia SU-556 de 2016 $6^{[41]}$, con el objetivo de dilucidar la temática. En dicha providencia se analizó la procedencia

37 Ibídem.

38 Poveda Cubilos, Guillermo. «Tutela contra laudo arbitral: una controversia sin fin». Revista de Derecho Publico, 2017: 1-20.

39 Ibídem.

40 Diego, Lopez Medina. El Derecho de los Jueces. (Legis, Ed.) Bogotá D.C, Colombia: Legis. Bogota: Legis Ediciones, 2001.

41 Colombia, Corte Constitucional de Colombia. Sentencia SU-556 de 2016. 13 de octubre de 2016, magistrada María Victoria Calle Correa. Disponible en http://www.corteconstitucional.gov.co/relatoria/2016/SU556-16.htm 
de una acción de tutela instaurada por el Banco de la República en contra de un laudo arbitral y la sentencia que resolvió el recurso de anulación que se presentó sobre el mismo. En la acción constitucional se afirmó que en el laudo y el fallo judicial se desconocieron los derechos fundamentales al debido proceso y a la igualdad, tras concluir que una póliza bancaria suscrita entre la parte demandante y unas compañías de seguros para amparar los riesgos derivados del servicio bancario no cubría aquellos relacionados con las condenas judiciales.

En la demanda de tutela se sostuvo que el laudo arbitral contenía: (i) un defecto orgánico, pues el mismo no había sido expedido en Derecho, pese a que Tribunal de arbitramento que lo profirió tenía la competencia para ello, (ii) un defecto sustantivo, en la medida en que había acudido a una norma inaplicable para resolver la controversia $y_{i}$ (iii) un defecto fáctico, debido a que no se contó con el apoyo probatorio para aplicar la norma que resolvió la controversia.

La acción de tutela, que fuera conocida por la Sección Cuarta del Consejo de Estado, fue negada. Para ello, señaló que ni el laudo ni la sentencia de anulación incurrieron en defectos orgánicos, pues el respectivo Tribunal de Arbitramento y la Sección Tercera del Consejo de Estado tenían la competencia para expedir el laudo y la providencia que resolvió el recurso de anulación de acuerdo con el clausulado de la póliza y el artículo 149 de la Ley 1437 de 2011. Se señaló que las providencias no incurrieron en un defecto sustantivo en la medida en que algunos de los artículos invocados no eran aplicables al caso y los demás fueron analizadas. También se concluyó que no se evidenciaron defectos fácticos en las providencias ya que el Tribunal, por un lado, valoró las pruebas aportadas, mientras que la Sección Tercera, por otro, argumentó que en sede de nulidad no era posible discutir asuntos probatorios, de allí que no pueda incurrir en un defecto fáctico. Finalmente, se indicó que no se había incurrido en un defecto procedimental si se tiene en cuenta que se estudiaron las causales invocadas en el recurso de anulación según se prevé en la Ley.

Remitido el expediente de tutela a la Corte Constitucional, esta última resolvió dejar sin efectos el laudo arbitral que definió las diferencias entre el Banco de la República y las compañías aseguradoras. Con tal fin, valoró, como primera medida, el cumplimiento de los requisitos generales de procedibilidad de la acción de tutela para reprochar tanto el laudo arbitral como la providencia que resolvió el recurso de anulación en su contra.

En este punto se aclaró que el juicio se hacía más estricto porque se trataba cuestionar un laudo arbitral, para lo cual se acudió a lo establecido en la sentencia SU-174 de $2007^{[42]}$, en donde se presentaron las siguientes premisas

42 Colombia, Corte Constitucional de Colombia. Sentencia SU-174 de 2007. 14 de marzo de 2007, magistrado Manuel José Cepeda Espinosa. Disponible en: http://www.corteconstitucional.gov.co/relatoria/2007/su174-07.htm. 
justificativas: (i) la necesidad de garantizar la estabilidad jurídica de los laudos; (ii) "la naturaleza excepcional y transitoria de la resolución de conflictos mediante arbitraje", (iii) "el respeto por la voluntad de las partes de someter la resolución de sus controversias ante árbitros y no ante jueces estatales"; y (iv) "la procedencia taxativa de las vías judiciales para controlar las decisiones proferidas por los árbitros".

El Tribunal constitucional concluyó que la acción de tutela contra la providencia que desató el recurso de anulación cumplía con los requisitos generales pues: (i) tenía relevancia constitucional ya que implicaba él estudió de la excepción de inconstitucionalidad contra el artículo 1624 inciso $1^{\circ}$ del Código Civil, entre otros fundamentos; cumplía con el requisito de: (ii) subsidiariedad, ya que frente a la sentencia del Consejo de Estado no eran procedentes los recursos ordinarios o extraordinarios previstos por el legislador; (iii) inmediatez, pues la acción constitucional fue presentada luego de un poco más de dos (2) meses de expedida la sentencia que resolvió el recurso de anulación, (iv) fue clara la exposición sobre la irregularidad procesal que se endilga en la providencia ${ }_{i}$ (v) se identificaron los hechos que generaron la presunta vulneración y porque ${ }_{i}$ (vi) la providencia objeto de reproche no es una sentencia de tutela.

Por otro lado, el Tribunal constitucional concluyó que la acción de tutela contra el laudo arbitral también cumplía con los requisitos generales en la medida en que: (i) los cuestionamientos contra el laudo tenían relevancia constitucional, pues no solo se busca establecer el alcance del principio de supremacía constitucional en el ámbito del arbitraje, sino que se debía determinar los mecanismos para garantizarla, entre otras razones ${ }_{i}$ (ii) contra el laudo arbitral procedía recurso de anulación, y el Banco de la República lo agotó. De allí que se cumpliera el requisito de subsidiariedad. (iii) Frente al requisito de inmediatez, se concluyó su cumplimiento en la medida en que se demostró la diligencia parte del Banco para reclamar la defensa de sus derechos; por otro lado, se había (iv) identificado con suficiencia los hechos que generaron la presunta vulneración de derechos tras la expedición del laudo $;$ (v) los cargos dirigidos contra el laudo no implicaban irregularidades procesales durante su trámite. En todo caso, se señaló que dicho requisito estaba superado puesto que el asunto podría implicar la necesidad de definir las atribuciones del Tribunal de arbitramento para dictar el laudo, su fundamento jurídico y su análisis probatorio. Finalmente, (vi) el laudo no es una sentencia de tutela.

Cumplidos los requisitos generales de procedencia, la Corte continuó con el análisis de los defectos o causales específicas endilgadas a dichas providencias judiciales. Frente a la primera de ellas, concluyó que no incurrió en los defectos procedimental y sustantivo. Sin embargo, la sentencia afirmó que el laudo arbitral contenía dos defectos sustantivos y un defecto fáctico en los siguientes términos: 
"(...) El laudo presenta entonces en suma tres defectos. Un defecto sustantivo originado en la manifiesta irrazonabilidad de su interpretación de elementos decisivos del negocio jurídico; un defecto sustantivo ocasionado por privar irrazonablemente de sus efectos a las normas pertinentes de la Constitución en la interpretación del negocio jurídico, y por sus visibles extravíos en la aplicación de una regulación y una conceptualización inatinente al contrato; y un defecto fáctico por la ostensible valoración irrazonable de los medios de prueba. Estos defectos están consecuencialmente conexos entre sí, y son jurídicamente dependientes del último, definitivo y más trascendental defecto fáctico y sustantivo por baber aplicado una norma claramente inaplicable al caso, dado que no se daba por demostrada razonablemente la concurrencia del supuesto fáctico previsto en ella. El Tribunal consideró que babía una duda remanente de todo el análisis, insuperable incluso con arreglo a cualquier otro recurso contractual, constitucional, legislativo o fáctico. Por lo mismo, apeló a una regla residual en materia de resolución de dudas contractuales, establecida en el artículo 1624 inciso 1 del Código Civil, conforme a la cual, si no bay otro remedio contra una ambigüedad en una cláusula, se escogerá el sentido que obre "a favor del deudor (... .)"43.

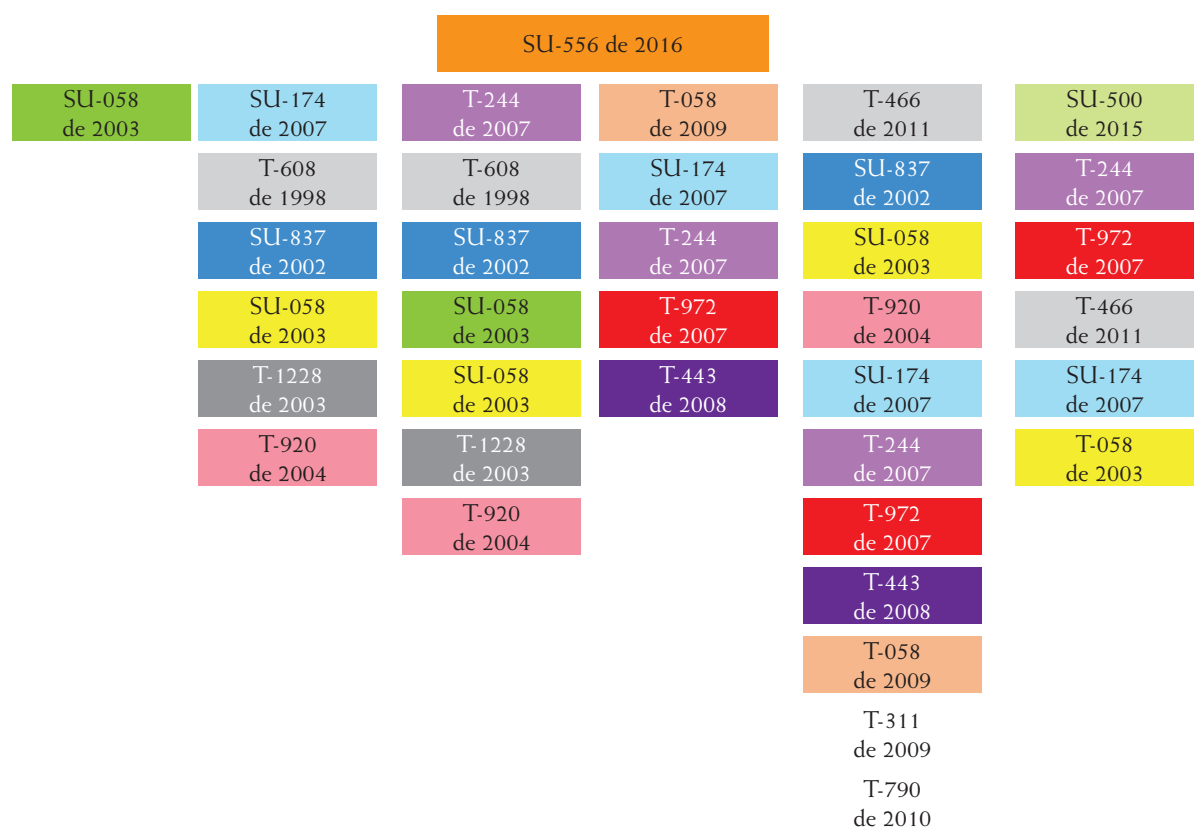

A partir de lo anterior, se ampararon los derechos fundamentales al debido proceso del Banco de la República y dejó sin efectos el laudo arbitral proferido por el Tribunal de Arbitramento convocado. La sentencia SU-556 de 2016 se apoyó en diferentes sentencias que aludían a la procedencia de la acción de tutela para controvertir un laudo arbitral y la providencia que desata un

43 Colombia, Corte Constitucional de Colombia. Sentencia Su-556 de 2016. 13 de octubre de 2016, magistrada María Victoria Calle Correa. Disponible en: http://www.corteconstitucional.gov.co/relatoria/2016/su556-16.htm 
recurso de anulación sobre el mismo. A continuación, se hace presenta una gráfica que refleja las sentencias que sirvieron de insumo (nicho citacional):

De acuerdo con la gráfica se puede concluir que las sentencias más citadas (puntos nodales), fueron las siguientes:

- Su-058 de $2003^{[44]}$ :

- T-244 de $2007^{[45]}$ :

- Su-174 de $2017^{[46]}$ :

- su-837 de $2002^{[47]}$ :

- T-920 de $2004^{[48]}$ :

- T-972 de $2007^{[49]}$ :

Las anteriores providencias se muestran como las más importantes en la línea jurisprudencial de la Corte Constitucional sobre la procedencia de la acción de tutela para controvertir tanto un laudo arbitral como la providencia que desata un recurso de anulación en su contra.

Las anteriores providencias se muestran como las más importantes en la línea jurisprudencial de la Corte Constitucional sobre la procedencia de la acción de tutela para controvertir tanto un laudo arbitral como la providencia que desata un recurso de anulación en su contra.

\section{CONCLUSIONES}

Como primera conclusión a la problemática planteada en este artículo en cumplimiento de su objetivo principal, es de señalar que uno de los primeros límites a la ejecutoriedad de los laudos arbitrales es la procedencia de los

44 Colombia, Corte Constitucional de Colombia. Sentencia Su-058 de 2003. 30 de enero de 2003, magistrado Eduardo Montealegre Lynett. Disponible en: http://www.corteconstitucional.gov.co/relatoria/2003/su058-03.htm.

45 Colombia, Corte Constitucional de Colombia. Sentencia T-244 de 2007. 30 de marzo de 2007, magistrado Humberto Antonio Sierra Porto. Disponible en: http://www.corteconstitucional.gov.co/relatoria/2007/T-244-07.htm.

46 Colombia, Corte Constitucional de Colombia. Sentencia T-174 de 2007. 14 de marzo de 2007, magistrado Manuel José Cepeda Espinosa. Disponible en: http://www.corteconstitucional.gov.co/relatoria/2007/su174-07.htm.

47 Colombia, Corte Constitucional de Colombia. Sentencia SU-837 de 2002. 9 de octubre de 2002, magistrado Manuel José Cepeda Espinosa. Disponible en: http://www.corteconstitucional.gov.co/relatoria/2002/Su837-02.htm.

48 Colombia, Corte Constitucional de Colombia. Sentencia T-920 de 2004. 23 de septiembre de 2004, magistrado Marco Gerardo Monroy Cabra. Disponible en: http://www.corteconstitucional.gov.co/relatoria/2004/T-920-04.htm.

49 Colombia, Corte Constitucional de Colombia. Sentencia T-972 de 2007. 15 de noviembre de 2007, magistrado Humberto Antonio Sierra Porto. Disponible en: http://www.corteconstitucional.gov.co/relatoria/2007/T-972-07.htm. 
recursos extraordinarios de anulación y revisión, ya que en la práctica, en algunos casos excepcionales, estos no cumplen con su objetivo principal de verificar los errores in procedendo no de detectados durante el curso del proceso arbitral por las partes y/o el árbitro conforme a las causales expresas en la ley para su procedencia.

Esta posición puede ser una de las más controvertidas en la actualidad, ya que para algunos el control jurisdiccional ejercido sobre los laudos arbitrales respecto a la procedencia del recurso extraordinario de anulación y revisión, es efectivo a fin de garantizar el debido proceso a todos los intervinientes y partes de un proceso arbitral.

Mientras que para otros es una clara vulneración del principio de la autonomía de la voluntad contractual, ya que con la procedencia de estos recursos extraordinarios, se desconoce el carácter de autoridad judicial y de ente encargado de administrar justicia que le asiste al árbitro en términos materiales respecto a su especialidad, especificidad, celeridad e inmediación en la manera de dirimir las controversias en el laudo arbitral, bajo el supuesto que cuando dicha decisión es revisada por la máxima autoridad jurisdiccional (Altos tribunales), en algunos casos, no se cuenta con la misma especialidad para decidir sobre una controversia material ya resulta por el árbitro.

Tales posiciones se apoyan en argumentos convincentes que se tienen que armonizar ya que, de un lado, si es necesario el control jurisdiccional cuando se presentan algunas de las excepciones consagradas en la Ley para la procedencia de estos recursos. Con ello no se desconocería la ejecutoriedad y el valor del laudo arbitral, pues no es lógico que en algunos casos los tribunales judiciales con la procedencia de estos recursos extraordinarios se extiendan en la revisión de aspectos materiales ya revisados y tratados por el árbitro en su decisión. Esta extensión, podría llegar a considerarse como un desconocimiento grave al principio de la autonomía de la voluntad contractual de las partes y a la función del Árbitro, que además de generar inseguridad jurídica para quienes acuden al arbitraje por sus ventajas antes expuestas, configura un vacío jurídico en cuanto a la libertad de las particulares respecto al modo de dirimir y solucionar sus controversias.

A efectos de enlazar estas conclusiones, se debe señalar que conforme a la jurisprudencia cuando dicho control jurisdiccional implica la afectación de un derecho fundamental, la Corte Constitucional ha determinado la procedencia de la acción de tutela como un segundo límite al principio de la autonomía de la voluntad contractual, la cual resulta procedente para controvertir los laudos arbitrales y las sentencias que resuelven los recursos de anulación que se presenten en contra de aquellos.

Pese a lo anterior, la admisión de dichas acciones de tutela está condicionada al cumplimiento de unos requisitos generales de procedencia y a que los laudos arbitrales y las providencia que definen el recurso de anulación, en todo caso, contengan algún defecto o causal que hagan procedente la acción de tutela. 
Es de destacar que la jurisprudencia ha venido señalada que el juicio constitucional sobre los laudos es más estricto. Ello, en atención a: (i) la necesidad de garantizar su estabilidad jurídica; (ii) la naturaleza excepcional y transitoria para la resolución de conflictos a través del arbitraje ${ }_{i}$ (iii) el respeto de la voluntad de las partes que optaron por someter sus diferencias a través del arbitramento $\mathrm{y}_{i}$ (iv) a la necesidad de acatar las normas que establecen las vías judiciales para controlar las decisiones de los árbitros.

Diferentes posiciones académicas han estudiado la procedencia del mecanismo de amparo colombiano contra los laudos arbitrales, planteando reflexiones desde la experiencia profesional en la esfera de la justicia arbitral, administrativa y constituciona $1^{50}$, describiendo los pronunciamientos que ha realizado la Corte sobre el particula $r^{51}$ y generando críticas constructivas sobre la materia en latinoamericana ${ }^{52}$ y desde la vision y ejercicio del ordenamiento jurídico colombiano ${ }^{53}$

De acuerdo con esta investigación y su respectiva línea jurisprudencial constitucional, se puede señalar que las conclusiones aquí expuestas se motivan a partir de la sentencia SU-556 de 2016, por ser el punto principal de apoyo. Luego, las sentencias SU-058 de 2003, T-244 de 2007 y SU-174 de 2017 se muestran como las providencias más determinantes (puntos nodales) en la medida en que tienen el mayor número de menciones (4) sobre la materia. No menos importantes resultan las sentencias SU-837 de 2002, T-920 de 2004 y T-972 de 2007 pues son citadas en tres (3) ocasiones.

\section{BIBLIOGRAFÍA}

Alexy, Robert. Teoria de los Derechos Fundamaentales. Madrid: Centro de Estudios Constitucionales, 1993.

Bejarano Guzman, Ramiro, Aida Patricia Hernàndez Silva, y Pablo Moreno CruZ. El Recurso de Anulacion de los laudos Arbitrales. Bogota: Universidad Externado de Colombia, 2019.

Bobbio, NorberTo. Teoría general del derecho. Quinta edición. Legis. Pagina 157. Bogota: Legis, 2016.

50 Gabriel, De Vega PinZON. «La acción de tutela contra laudos arbitrales. Breve análisis a partir de la jurisprudencia constitucional». Óp. cit, p. 37.

51 JORGE ENRIQUE, IBANEZ NAJAR. La acción de tutela contra laudos arbitrales. Óp. cit, p. 38.

52 Pablo, Rey Vallejo. «El Arbitraje y los Ordenamientos Jurídicos en Latinoamérica: un estudio sobre formalización y judicialización. Vniversitas». Óp. cit, p. 39.

53 Poveda Cubilos, Guillermo. «Tutela contra laudo arbitral: una controversia sin fin». Óp. cit, p. 41. 
CORREA, ANGEL DiAnA. «El reconocimiento y la ejecucion de un laudo internacional anulado en el pais de la sede arbitral».e-Mercatoria, vol. 7, n. ${ }^{\circ} 2$ (2008): 2-8.

De VeGa Pinzon, GabRiEL. «La acción de tutela contra laudos arbitrales. Breve análisis a partir de la jurisprudencia constitucional». Revista de la Academia Colombiana de Jurisprudencia. Arbitraje, conciliación, amigable composición y doctrina, 2018: 43-64.

FERnANDEZ ROZAS, JOSE CARLOS. Tratado del arbitraje comercial en america latina. Bogota: Portal del Derecho S.A, 2008.

Gamboa Morales, ERnesto. El arbitraje en equidad. Bogota: Academia Colombiana de Jurisprudencia, 2003.

Hinestrosa, Fernando. «Autonomia privada y tipicidad Contratual». Revista de Derecho Privado, n. ${ }^{\circ} 24$ (Enero-Junio 2013): 2-11.

IBANEZ NAJAR, JORGE ENRIQUE. La acción de tutela contra laudos arbitrales. Bogota: Pontificia Universidad Javeriana, 2009.

LÒPEZ DAZA, GERMAn AlFOnSO. «El juez constitucional colombiano como legislador positivo: ¿un gobierno de los jueces?». Cuestiones constitucionales 24 (ene./ jun. 2011): 1-5.

Lopez Medina, Diego. El Derecho de los Jueces. (Legis, Ed.) Bogotá D.C, Colombia: Legis. Bogota: Legis Ediciones, 2001.

Poveda Cubilos, Guillermo. «Tutela contra laudo arbitral: una controversia sin fin». Revista de Derecho Publico, 2017: 1-20.

Quinche RAmiReZ, MANUEL FERnANDO. Vías de becho. Acción de tutela contra providencias. Bogota: Univesidad del Rosario, 2007.

Rey Vallejo, Pablo. «El Arbitraje y los Ordenamientos Jurídicos en Latinoamérica: un estudio sobre formalización y judicialización. Vniversitas(126), 199-237». Vniversitas, 2013: 199-237.

\section{JURISPRUDENCIA Y NORMAS COMPLEMENTARIAS}

Colombia. Corte Constitucional de Colombia. Sentencia T-774 de 2004. 13 de agosto de 2004, magistrado Manuel José Cepeda Espinosa. Disponible en: http://www. corteconstitucional.gov.co/RELATORIA/2004/T-774-04.htm.

Colombia, Corte Constitucional de Colombia. Sentencia Su-556 de 2016. 13 de octubre de 2016, magistrada María Victoria Calle Correa. Disponible en: http:// www.corteconstitucional.gov.co/relatoria/2016/su556-16.htm 
Colombia, Corte Constitucional de Colombia. Sentencia SU-400 de 2012. 31 de mayo de 2012, magistrada Adriana María Guillén Arango. Disponible en: http:// www.corteconstitucional.gov.co/relatoria/2012/SU400-12.htm.

Colombia, Corte Constitucional de Colombia. Sentencia SU-174 de 2007. 14 de marzo de 2007, magistrado Manuel José Cepeda Espinosa. Disponible en: http://www. corteconstitucional.gov.co/relatoria/2007/su174-07.htm.

Colombia, Corte Constitucional de Colombia. Sentencia SU-058 de 2003. 30 de enero de 2003, magistrado Eduardo Montealegre Lynett. Disponible en: http:// www.corteconstitucional.gov.co/relatoria/2003/Su058-03.htm.

Colombia, Corte Constitucional de Colombia. Sentencia T-244 de 2007. 30 de marzo de 2007, magistrado Humberto Antonio Sierra Porto. Disponible en: http://www. corteconstitucional.gov.co/relatoria/2007/T-244-07.htm.

Colombia, Corte Constitucional de Colombia. Sentencia T-174 de 2007. 14 de marzo de 2007, magistrado Manuel José Cepeda Espinosa. Disponible en: http://www. corteconstitucional.gov.co/relatoria/2007/Su174-07.htm.

Colombia, Corte Constitucional de Colombia. Sentencia Su-837 de 2002. 9 de octubre de 2002, magistrado Manuel José Cepeda Espinosa. Disponible en: http:// www.corteconstitucional.gov.co/relatoria/2002/SU837-02.htm.

Colombia, Corte Constitucional de Colombia. Sentencia T-920 de 2004. 23 de septiembre de 2004, magistrado Marco Gerardo Monroy Cabra. Disponible en: http://www.corteconstitucional.gov.co/relatoria/2004/T-920-04.htm.

Colombia, Corte Constitucional de Colombia. Sentencia T-972 de 2007. 15 de noviembre de 2007, magistrado Humberto Antonio Sierra Porto. Disponible en: http://www.corteconstitucional.gov.co/relatoria/2007/T-972-07.htm.

Pacto Internacional de Derechos Civiles y Políticos. Adoptado y abierto a la firma, ratificación y adhesión por la Asamblea General en su resolución 2200 A (XXI), de 16 de diciembre de 1966 Entrada en vigor: 23 de marzo de 1976, de conformidad con el artículo 49 Lista de los Estados que han ratificado el pacto, dentro del cual se encuentra Colombia. 